\title{
Technical and Economic Sustainability of Concrete Pavements
}

\author{
Laura Moretti ${ }^{1}$ \\ ${ }^{1}$ Department of Civil, Construction and Environmental Engineering, Sapienza, Università di Roma, Rome, Italy \\ Correspondence: Laura Moretti, Department of Civil, Constructional and Environmental Engineering, Sapienza, \\ Università di Roma, Rome, Italy. Tel: 39-6-4458-5124. E-mail: laura.moretti@uniroma1.it
}

Received: January 30, 2014

Accepted: March 13, $2014 \quad$ Online Published: April 8, 2014

doi:10.5539/mas.v8n3p1

URL: http://dx.doi.org/10.5539/mas.v8n3p1

\begin{abstract}
Economic evaluation of road pavements is as important as their technical and structural design: often only initial construction costs are calculated to assess economic project sustainability. Instead, forgetting maintenance costs exposes society to unacceptable risks of expensive and incorrect decisions.

Road pavements design and construction solutions affect maintenance works during service life, which not only entail economical and financial expenditures, but also damage service regularity for users and affect environmental impact. The analysis of pavement distress and the study of its evolution during service life can contribute to find the financially most advantageous solution.

This paper shows a software program developed to analyze structural, functional and financial performances of road concrete pavements both doweled slabs and continuously reinforced.
\end{abstract}

Keywords: sustainability, concrete pavements, design, maintenance, present value

\section{Introduction}

In the project phase, it's important to evaluate and guarantee an adequate level of service during the service life. The experience proves that road concrete pavements are durable, so the technicians should consider the structural and functional performance year by year. It affects pavement management system and its social and environmental costs during operation phase (Di Mascio, 2002; D'Andrea et al., 2004). The analysis of road work costs can contribute to finding the most advantageous solution, also considering the functional performances of road pavements (Loprencipe \& Cantisani, 2013). In fact, the financial analysis during all service life could modify the stakeholders' choice (Abdullahi et al., 2013) and it could guarantee expenditure programmes under specified budget constraints.

In this paper, the design procedure for Jointed Plain Concrete Pavement (JPCP) is presented. This procedure involves the use of structural models to calculate pavement response and the implementation of distress predictive models to monitor the performance during the evaluation period. Mechanical and functional pavement response, based on critical stresses due to repeated traffic and environmental loading, is evaluated by automatic calculation procedures. A Visual Basic for Application (VBA) code, named ESC (Economic Sustainability of Concrete pavement), has been implemented to analyze input data and give structural and functional solution implementing fatigue and decay curves (Moretti, 2012).

In this model, mechanistic and empirical pavement distress models, proposed by AASHTO Guide 2002 (2008) and Gulen et al. (2001), are used to evaluate pavement condition and define automatically maintenance and repair procedures.

The structural analysis concerns the stresses in concrete at first load and the fatigue damage; the functional analysis concerns the transverse cracking and the International Roughness Index (IRI).

Indeed, structural, material and site-specific environmental data inputs and calculated stresses are used to verify pavement at construction year and to evaluate, year by year, pavement condition during service life. Maintenance plan is derived from international experience (scheduled and preventive maintenance) and effective condition (corrective maintenance).

The tool calculates together the capital resources to be implemented by road operator. The construction costs are calculated considering data listed in the bill of quantities, while maintenance costs are derived from maintenance plan. Given the inflation rate and the discount rate, in this study supposed both constant during all pavement 
service life, ESC calculates the Present Value (PV), a synthetic evaluation methodology of economic and financial charges correlated to verified pavement.

\section{Software Design Model}

Factors influencing pavement design are: traffic, environmental conditions, subgrade bearing capacity and materials characteristics.

ESC consist of default Microsoft Excel® worksheets to input design data. Construction and maintenance costs are derived from project geometrical characteristics, materials, labour, machinery and equipment unit costs. Joints, dowel bars and tie bars amount are automatically calculated by ESC; results have been verified with a finite-element model (Bonin et al., 2007).

The thermal pattern of road concrete pavements generates stresses comparable to stresses related to traffic loads (Chai et al., 2012; Qin \& Hiller, 2011; Nishizawa et al., 2009; Faraggi et al., 1987), so in the program has been implemented an innovative verified thermal model to describe temperature in slab thickness and calculate thermal stresses.

\subsection{Thermal Model}

Pavement thermal pattern of concrete pavements, influenced by air temperature, sun's radiation, wind speed and thermal properties of concrete, is usually described by Barber theory (1957). It defined a sinusoidal function to describe the solution of the one-dimensional problem of heat transfer across a semi-infinite, isotropic, homogeneous solid surface which is in a steady regime, although periodic, with a boundary sinusoidal temperature variation forced in the surface, as in Equation 1:

$$
T(z, t)=T_{a g}+\Delta T \cdot \sin (2 \pi \cdot t / \tau-z \sqrt{\pi / d \cdot \tau})
$$

$T_{a g}$ is the average daily air temperature, $\Delta T$ is the differential thermal amplitude, $t$ is the time, $z$ is the pavement depth and $\tau$ is the period of temperature variation.

Furthermore, for semi-infinite medium, the theoretical phase displacement $\varphi$ and damping values $\gamma$ are shown in Equation 2 and Equation 3 respectively:

$$
\varphi=\kappa \cdot z \cdot \tau / 2 \pi
$$

where $k$ is the thermal conductivity of concrete.

$$
\gamma=\sqrt{\pi / a \cdot \tau}
$$

The Barber formula to evaluate thermal gradients during the day and the night of all seasons is in Equation 4:

$$
\operatorname{Tpav}(z, t)=T_{a g}+R+\left(\frac{A_{g}}{2}+3 R\right) \cdot F \cdot \exp (-C \cdot z) \cdot \sin \left(0.262 t-C \cdot z-\arctan \frac{C}{H+C}\right)
$$

where $\operatorname{Tpav}(z, t)$ is the temperature of pavement at depth $z$ at hour $h ; T_{a g}$ is the average seasonal daily air temperature; $R$ is the daily solar radiation contribution to air temperature expressed by Equation 5 :

$$
R=\frac{2 \cdot b \cdot I}{3 \cdot 24 \cdot h}
$$

$A_{g}$ is the daily range in air temperature; $b$ is the surface absorptivity to the total solar radiation; $I$ is the daily solar radiation; $h$ is the heat transfer coefficient, expressed by Equation 6:

$$
h=4.882 \cdot\left(1.3+0.4332 \cdot v^{0.75}\right)
$$

$v$ is the average wind speed; $F$ is expressed by Equation 7; $H$ is expressed by Equation 8 and $C$ is expressed by Equation 9:

$$
\begin{gathered}
F=\frac{H}{\sqrt{(H+C)^{2}+C^{2}}} \\
H=\frac{h}{k}
\end{gathered}
$$

where $k$ is thermal conductivity of concrete; 


$$
C=\frac{0.131 \cdot s \cdot \gamma}{k}
$$

where $s$ is specific heat of concrete and $\gamma$ is density of concrete.

Having the same maximum and minimum temperatures, Barber's model and Thomlinson's model (1940) curves are almost overlapping, but the real development of pavement temperature during a cloudless day is not sinusoidal, because ground solar radiation changes during the daytime (Rao et al., 2001) and is not symmetric with respect to its average value. So, in the thermal model entered in ESC has been implemented the Faraggi, Jofré and Kraemer integrated with Barber's model (Faraggi et al., 1987).

New thermal law (Moretti et al., 2013a) is valid both for flexible and for rigid pavements. It calculates daily temperature range by the Barber's theory, which returns a closed form solution, and defines non symmetric sinusoidal trend of temperatures by Faraggi et al. model. Equation 10 is valid between sunrise and zenith, Equation 11 is valid between zenith and sunrise.

$$
\begin{gathered}
T(z, t)=T_{a g}+R+\left(\frac{A_{g}}{2}+3 R\right) \cdot F \cdot e^{-C z} \cdot \sin \left(\frac{2 t-S_{h}}{2 S_{h}} \pi-z \sqrt{\frac{\pi \cdot \gamma \cdot c_{s}}{24 \cdot k}}\right) \\
T(z, t)=T_{a g}+R+\left(\frac{A_{g}}{2}+3 R\right) \cdot F \cdot e^{-C z} \cdot \operatorname{sen}\left(\frac{4\left(t+S_{n}\right)-S_{a}}{2 S_{a}} \pi-z \sqrt{\frac{\pi \cdot \gamma \cdot c_{s}}{24 \cdot k}}\right)
\end{gathered}
$$

where $T_{s g}, R, A_{g}, C$ and $F$ has been described above, $S_{h}$ is the number of hours between sunrise and zenith and $S_{n}$ is the number of hours between sunset and the next sunrise. $S_{h}, S_{a}$ and $S_{n}$ values must satisfy the conditions expressed in Equation 12 and Equation 13:

$$
\begin{gathered}
2 S_{h}+S_{n}=24 \\
\mathrm{~S}_{\mathrm{a}}=2 \cdot\left(S_{h}+S_{n}\right)
\end{gathered}
$$

In the thermal curves, $\mathrm{t}=0$ coincides with the sunrise hour.

Daily thermal gradients derived by the modified Faraggi et al. theory are consistent with measured values: in the night the thermal gradients are next to half of those ones during the day. User inputs thermal seasonal data, so for each 24 hours of the four season the VBA code calculates thermal pavement conditions.

\subsection{Technical Analysis}

Pavement bearing capacity is defined by modulus of reaction: this parameter depends on thickness and type of subbase layers (granular and/or cement treated subbase) and on modulus of subgrade reaction. The modulus of subbase reaction is automatically provided by ESC code, using Packard charts; maximum permitted modulus of reaction value is $130 \mathrm{MPa} / \mathrm{m}$ as recommended in the most of literature references (Domenichini, 1984).

In the computer code, datasheets are provided to input traffic level, establishing average daily heavy vehicles per lane at the road opening year, annual rate of traffic growth, pavement service life, traffic spectrum and hourly distribution per vehicle type. ESC has in its datasheet all traffic spectra defined in the Italian Pavement Design Catalogue (CNR, 1995; Domenichini et al., 1993), but user can defines any other traffic spectrum.

The combination of frequency between thermal gradients and different load configuration during the night and day hours affects the number of repetitions for fatigue calculation. This value has been used also in evaluation of cracking damage (D'Andrea \& Fiore, 2003).

Requested data inputs about concrete are: materials amounts and composition of concrete mix (water, cement, aggregates, chemical admixtures); physical and thermal properties of concrete (density, coefficient of absorption of the solar radiation, specific heat, thermal conductivity, Poisson's ratio, cubic characteristic compressive strength of concrete). Elastic modulus is automatically deducted from characteristic cubic compressive strength $\left(\mathrm{R}_{\mathrm{ck}}\right)$.

Depending on the thermal state of the pavement, the calculation model iteratively identifies the structural calculation equation corresponding to the boundary conditions. The theory of Westergaard, the formulas proposed by VENCON-CROW and the analytical solutions of the elastic theory of thin plates are used to obtain stresses by closed form solution, while in Di Mascio et al. (2012) Kenslabs, a finite element software, calculated the stresses in pavement. Results from the proposed model have been validated by the cited structural software. Given the superposition principle, the thermal stresses are derived through an iterative process that modifies the 
theory of Eisenmann according to the thermal and structural models above defined.

Fatigue damage is calculated year by year, load by load and hour by hour, with equation of PCA, Bradbury's law, Bennet-Raju's law, Kesler's law, Sawan-Darter's law and equation proposed by MEPDG for JPCP. The maximum calculated value of cumulative fatigue damage index has been used to verify with respect to fatigue the pavement.

The analysis model annually assesses the fatigue level reached and the service level of the designed pavement, planning scheduled or failure maintenance as the status of indicators changes. Strategies of preventive maintenance schedule joint sealing and full depth repair (to restore potholes). Rehabilitation strategies of corrective maintenance schedule diamond grinding to correct roughness and full depth repair to restore slabs cracked (AAVV, 2007; Shahin, 2005).

Distress models used in this analysis are: cracking model by AASHTO Guide 2002 shown in Equation 14 and IRI model by empirical equation proposed by Gulen et al. shown in Equation 15.

$$
\mathrm{C} R K=\frac{A}{1+F D \cdot^{-1.68}}
$$

where $\mathrm{C} R K$ is the cracking damage in percent and $F D$ is the cumulative fatigue damage.

$$
I R I=I R I_{0}+C_{1} \cdot A G E+C_{2} \cdot A A D T
$$

where $I R I$ is the predicted value of $I R I, I R I_{0}$ is the IRI value at the construction year, $A G E$ is the year of service life, $A A D T$ is the annual average daily truck, $C_{1}$ and $C_{2}$ are corrective coefficients.

\subsection{Economic Analysis}

The economic impact of the pavement is assessed, as the cost per unit of surface, through the synthetic indicator Present Value. Despite the extreme difficulty of this approach towards a system so vast and multi-sectorial, the indicator calculated by ESC allows more objectively comparisons between design solutions. It takes into account the cash flows generated by the initial cost of construction and maintenance costs discounted at the year of construction. Their sum plus construction costs is the Present Value of project.

The indicator allows not only to assess the proposed solution, but above to compare other concrete pavements also with semi-rigid and flexible pavements. The program also returns a chart of trend of nominal costs incurred during the service life of the pavement (Debroux et al., 2007) or of the railway track (Di Mascio et al., 2014a, 2014b). From this chart is possible to find the year when a solution is more convenient than other compared.

\section{Case Study}

Three highways Jointed Plain Concrete Pavements listed in the Italian catalogue of road pavements have verified. Each pavement structure consists of a concrete slabs, a subbase, cement-treated layer $15 \mathrm{~cm}$ thick, and an unbound granular mix layer $15 \mathrm{~cm}$ thick; subgrade resilient modulus is equal to $90 \mathrm{MPa}$. Slabs are 27, 26 and 24 $\mathrm{cm}$ thick for a cumulative heavy traffic respectively equal to 45,25 and 10 millions of passages.

The $\mathrm{R}_{\mathrm{ck}}$ of concrete is $55 \mathrm{MPa}$; the modulus of rupture of concrete (MOR) is calculated with formula proposed in software package VENCON2.0; It's expressed by Equation 16 (Houben, 2009).

$$
M O R=1.3 \cdot[(1600-h) / 1000] \cdot\left[1.05+0.05 \cdot\left(R_{c k}+8\right)\right] / 1.2
$$

where $h$ is the thickness of the concrete slab in mm and MOR is in MPa.

The annual increase of concrete strength during service life has been considered. Examined concrete slabs were $400 \mathrm{~cm}$ long and $380 \mathrm{~cm}$ large. Pavement design life is 40 years.

Single (SL) or dual layer (DL) labs with (EAS) or without exposed aggregate surface (NEAS), with metallic or plastic dowel chairs, are examined.

All examined pavements are fatigue tested: fatigue damage (FD) is less than 1 at the end of service life, as represented in Table 1. 
Table 1. Fatigue Damage (FD)

\begin{tabular}{ll}
\hline Slab thickness $(\mathrm{cm})$ & FD \\
\hline 24 & $1.80 \mathrm{E}-01$ \\
26 & $1.30 \mathrm{E}-01$ \\
27 & $1.49 \mathrm{E}-01$ \\
\hline
\end{tabular}

Threshold values of transverse cracking and IRI are listed in Table 2.

Table 2. Threshold value distresses

\begin{tabular}{ll}
\hline Transverse cracking (\%) & 10 \\
IRI $(\mathrm{m} / \mathrm{km})$ & 2.5 \\
\hline
\end{tabular}

Corrective maintenance results to be necessary at the years shown is Table 3 .

Table 3. Year of service life when threshold limit is achieved

\begin{tabular}{lll}
\hline \multirow{2}{*}{$\begin{array}{l}\text { Slab } \\
\mathrm{cm})\end{array}$} & thickness & \multicolumn{2}{l}{ Year when threshold limit is achieved (year) } \\
\cline { 2 - 3 } & Transverse cracking & IRI \\
\hline 24 & $>40$ & 34 \\
26 & $>40$ & 34 \\
27 & $>40$ & 34 \\
\hline
\end{tabular}

During their service life, the examined pavements don't need for the corrective maintenance caused transverse cracking, whereas they need for grinding across the traffic lanes due to roughness progression.

Construction costs are listed in Table 4 and in Table 5.

Table 4. Construction costs $\left(\mathrm{C}_{\mathrm{C}}\right)$, cases with metallic dowel chairs

\begin{tabular}{lllll}
\hline \multirow{2}{*}{$\begin{array}{l}\text { Slab } \\
(\mathrm{cm})\end{array}$} & thickness & \multicolumn{3}{c}{$\mathrm{C}_{\mathrm{C}}\left(€ / \mathrm{m}^{2}\right)$} \\
\cline { 2 - 5 } & EAS+DL & NEAS+DL & EAS+SL & NEAS+SL \\
\hline 24 & 55.51 & 51.81 & 55.10 & 51.4 \\
26 & 57.40 & 53.70 & 57.08 & 53.38 \\
27 & 58.42 & 54.72 & 58.08 & 54.38 \\
\hline
\end{tabular}

Table 5. Construction costs $\left(\mathrm{C}_{\mathrm{C}}\right)$, cases with plastic dowel chairs

\begin{tabular}{lllll}
\hline \multirow{2}{*}{$\begin{array}{l}\text { Slab } \\
(\mathrm{cm})\end{array}$} & thickness & \multicolumn{3}{c}{$\mathrm{C}_{\mathrm{C}}\left(€ / \mathrm{m}^{2}\right)$} \\
\cline { 2 - 5 } & EAS+DL & NEAS+DL & EAS+SL & NEAS+SL \\
\hline 24 & 52.75 & 49.05 & 52.34 & 48.64 \\
26 & 54.79 & 51.09 & 54.46 & 50.76 \\
27 & 55.78 & 52.08 & 55.44 & 51.74 \\
\hline
\end{tabular}

Preventive maintenance strategies defined for these pavements are listed in Table 6, as suggested in literature. Corrective actions are planned according to Table 3. 
Table 6. Preventive maintenance

\begin{tabular}{llll}
\hline Preventive maintenance work & Year & \multicolumn{2}{l}{ Quantity } \\
\hline Joint sealing & 10 & $100 \%$ & Total joint length \\
Full depth patching & 10 & $2 \%$ & Total area \\
Joint sealing & 15 & $60 \%$ & Total joint length \\
Joint sealing & 20 & $60 \%$ & Total joint length \\
Full depth patching & 20 & $2 \%$ & Total area \\
Joint sealing & 25 & $60 \%$ & Total joint length \\
Joint sealing & 30 & $60 \%$ & Total joint length \\
Full depth patching & 30 & $2 \%$ & Total area \\
Joint sealing & 35 & $60 \%$ & Total joint length \\
\hline
\end{tabular}

Nominal maintenance costs are calculated knowing type, extension and timetable of maintenance and rehabilitation works, as expresses by Equation 17.

$$
C_{x}=C_{0}(1+i)^{x}
$$

where $C_{x}$ is the maintenance cost incurred in year $x ; C_{0}$ is the maintenance cost at construction year; $i$ is the annual inflation rate equal to $3 \%$. This supposed value is the average value of the eighteen last years in Italy (Camera di Commercio di Reggio Emilia, 2012); $x$ is the time in the future in years. Figure 1 shows cumulated nominal costs during design life of $24 \mathrm{~cm}$ thick EAS+DL pavements with metallic dowel chairs.

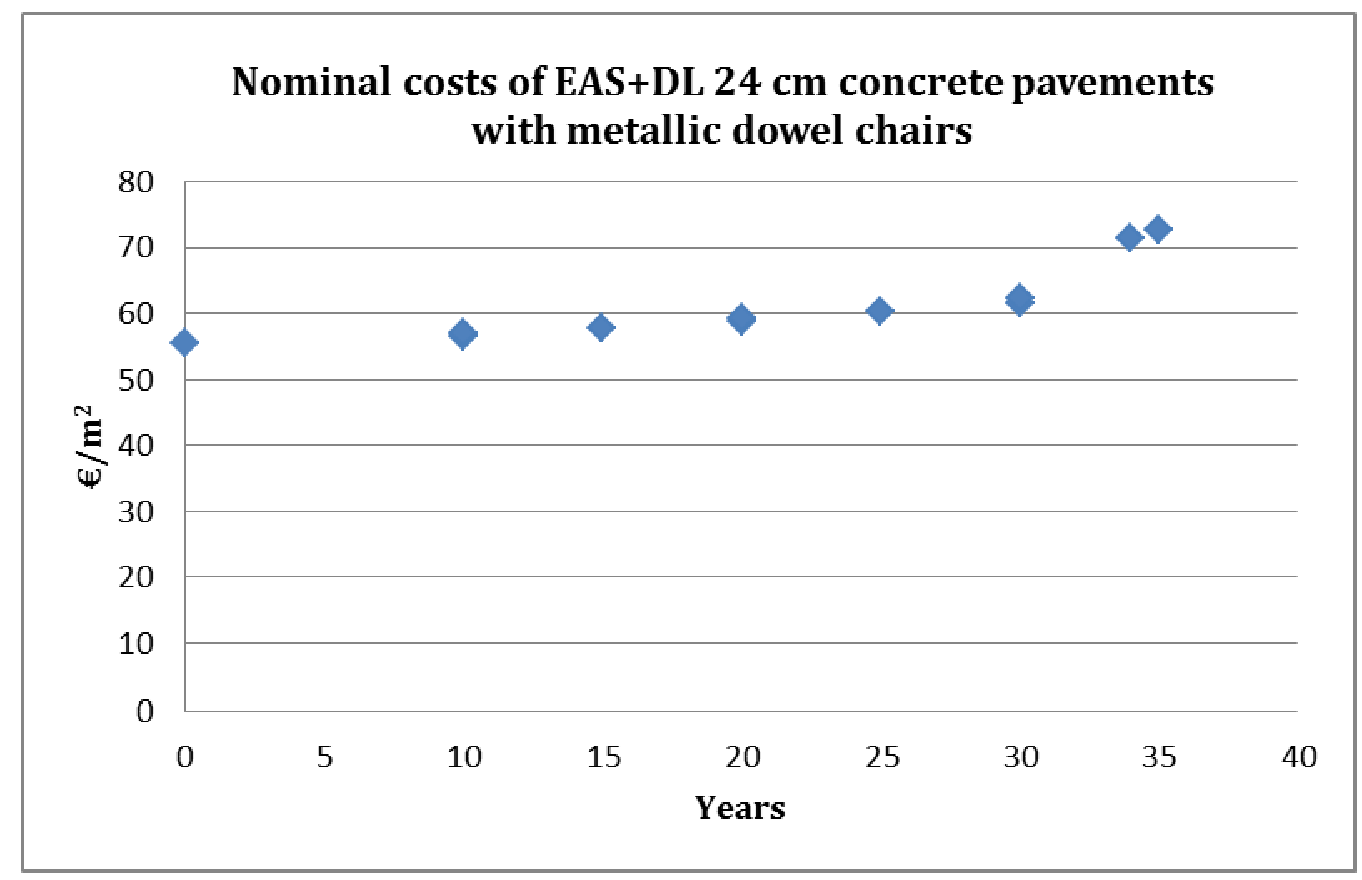

Figure 1. Cumulated nominal costs

Actual maintenance costs are calculated as expressed by Equation 18:

$$
C_{A, x}=\frac{C_{x}}{(1+r)^{x}}
$$

where $C_{A, x}$ is the maintenance cost discounted at construction year $x ; r$ is the annual discount rate equal to $4 \%$ (the risk premium for the investment is equal to 1\%) (Banca d'Italia, 2014; European Central Bank, 2014). 
The Present Value of this series of costs is calculated as expressed by Equation 19:

$$
P V=C_{C}+\sum_{x=1}^{N} C_{A, x}
$$

where $C_{C}$ is construction cost incurred in year 0 and $N$ is the number of years in the analysis period.

Table 7 and Table 8 show the obtained PV, respectively for pavements with metallic and plastic dowel chairs, in euro $/ \mathrm{m}^{2}$.

Table 7. PV of pavement investment, cases with metallic dowel chairs

\begin{tabular}{lllll}
\hline \multirow{2}{*}{$\begin{array}{l}\text { Slab } \\
(\mathrm{cm})\end{array}$} & EAS+DL & NEAS+DL & EAS+SL & NEAS+SL \\
\cline { 2 - 5 } & 60.1 & 62.7 & 59.7 & 62.3 \\
24 & 62.1 & 64.7 & 61.7 & 64.4 \\
26 & 63.1 & 65.7 & 62.8 & 65.4 \\
\hline
\end{tabular}

Table 8. PV of pavement investment, cases with plastic dowel chairs

\begin{tabular}{lllll}
\hline \multirow{2}{*}{$\begin{array}{l}\text { Slab } \\
(\mathrm{cm})\end{array}$} & thickness & \multicolumn{3}{c}{$\mathrm{PV}\left(€ / \mathrm{m}^{2}\right)$} \\
\cline { 2 - 5 } & EAS+DL & NEAS+DL & EAS+SL & NEAS+SL \\
\hline 24 & 57.3 & 59.9 & 56.9 & 59.5 \\
26 & 59.5 & 62.1 & 59.1 & 61.8 \\
27 & 60.5 & 63.1 & 60.1 & 62.8 \\
\hline
\end{tabular}

Results obtained are comparable with values in literature: concrete pavements are more expensive initially, but need limited work maintenance, so are economically competitive versus other common solutions, as bituminous pavements. Indeed, for the examined pavements, the average construction cost is $53.7 € / \mathrm{m}^{2}$, but only $7.8 € / \mathrm{m}^{2}$ average discounted maintenance cost needs during 40 years of service life.

\section{Conclusions}

The structural and functional characteristics of concrete pavements have been evaluated by ESC, the proposed automatic procedure in VBA code. The method defines pavement management system during service life and calculates the Present Value (PV) of designed and verified solution. This tool is a quick, simple and user-friendly instrument to estimate total costs in concrete pavements: the procedure is a forward-looking decision framework that assess life time costs in addition to construction costs. The new approach could be used to evaluate economic and technical sustainability of JPCP and to compare different types of both rigid and flexible pavements.

The current study has practical implications as well. The model could be a valid tool for designers and decision-makers. User defines road classes in terms of climatic condition, traffic and subgrade bearing capacity and he designs the structure of pavements and road works: the program calculates the PV needed to implement the solution. The proposed maintenance and rehabilitation policy may be modified to optimize strategies on performance and costs.

The instruments will be integrated in a program written by author to evaluate environmental sustainability of roads (Moretti et al., 2013b). The final software will allow to compare alternative considering not only the construction, maintenance and rehabilitation costs, but also the environmental impacts of examined solution. The multicriteria analysis approach will synthetize the summarizes the complex, often competing, technical and economic aspects (Dano et al., 2011).

\section{References}

AASHTO. (2008). Mechanistic-Empirical Pavement Design Guide - A Manual of Practice. AASHTO, Washington, DC: USA.

AAVV. (2007). Long-Life Concrete Pavements in Europe and Canada. U.S. Department of Transportation 
Federal Highway Administration. Report no. FHWA-PL-07-027.

Abdullahi, A. U., Noor Amila Wan, A. Z., Mohd, F. K., \& Arazi, I. (2013). Stakeholder Perceptions on Achieved Benefits of PFI Procurement Strategy. Modern Applied Science, 7(4), 31-40. http://dx.doi.org/10.5539/mas.v7n4p31

Banca d'Italia. (2014). Retrieved January 28, 2014, from http://www.bancaditalia.it/

Barber, E. S. (1957). Calculation of maximum pavement temperatures from weather report. HRB Bulletin 168, National Research Council, Washington, DC: USA.

Bonin, G., Cantisani, G., Loprencipe, G., \& Ranzo, A. (2007). Dynamic effects in concrete airport pavement joints. [Effetti dinamici nei giunti delle pavimentazioni aeroportuali in calcestruzzo]. Industria Italiana Del Cemento, 77(834), 590-607.

Camera di Commercio di Reggio Emilia. (2012). Retrieved April 12, 2012, from http://www.re.camcom.gov.it/

Chai, G., van Staden, R., Guan, H., \& Loo, Y. (2012). Impact of climate related changes in temperature on concrete pavement: a finite element study. Paper presented at the $25^{\text {th }}$ ARRB Conference - Shaping the future: Linking policy, research and outcomes, Perth, Australia 2012.

CNR. (1995). Catalogo delle Pavimentazioni Stradali. B.U. 178.

D'Andrea, A., \& Fiore, N. (2003). Fatigue life of asphalt concrete with rubber grains. Paper presented at the Advances in Damage Mechanics (pp. 65-74). http://dx.doi.org/10.2495/FDM030071

D’Andrea, A., Bonora, V., \& Drago, D. (2004). Asphalt concrete with bottom ash: Environmental aspects. Paper presented at the Proceedings of the International Conference on Restoration, Recycling and Rejuvenation Technology for Engineering and Architecture Application (pp. 56-63).

Dano, U. L., Abdul-Nasir, M., \& Abdul-Lateef, B. (2011). A Geographic Information System and Multi-Criteria Decision Analysis in Proposing New Recreational Park Sites in Universiti Teknologi Malaysia. Modern Applied Science, 5(3), 39-55.

Debroux, R., Kral, Z., Lemlin, M., Wansart, L., Degraeve, M., Haesen, G., \& Di Mascio, P. (2007). Bituminous and continuously reinforced concrete pavements for motorways. An economic comparison (part II). [Pavimentazioni Bituminose ed in Calcestruzzo ad Armatura Continua per Autostrade. un Confronto Economico (II Parte)]. Industria Italiana Del Cemento, 77(830), 288-299.

Di Mascio, P. (2002). Concrete pavements and interlocking concrete paving blocks for low-volume roads. [Le pavimentazioni per la viabilità minore in calcestruzzo e in masselli autobloccanti]. Industria Italiana Del Cemento, 72(DEC.), 968-991.

Di Mascio, P., Loprencipe, G., \& Maggioni, F. (2014a). Modellazione del comportamento visco-elastico degli strati della sede ferroviaria [Visco-elastic modeling for railway track structure layers]. Ingegneria Ferroviaria, 69(3), 207-222.

Di Mascio, P., Loprencipe, G., \& Moretti, L. (2014b). Competition in rail transport: methodology to evaluate economic impact of new trains on track, 3rd International Conference on Transportation Infrastructure ICTI2014 - Sustainability, Eco-efficiency and Conservation in Transportation Infrastructure Asset Management, Pisa, 22-25 April 2014. (In press).

Di Mascio, P., Moretti, L., \& Panunzi, F. (2012). Economic Sustainability of Concrete Pavements. Procedia Social and Behavioral Sciences, 53, 125-133. Proceedings, V International SIIV Congress Sustainability of Road Infrastructures, Rome, Italy, 29th-31st October 2012.

Domenichini, L. (1984). Pavimentazioni stradali in calcestruzzo - Progettazione/esecuzione/manutenzione. A.I.T.E.C.- Associazione Italiana Tecnico Economica del Cemento.

Domenichini, L., Di Mascio, P., Giannattasio, P., Caliendo, C., Festa, B., Marchionna, A., ... Paoloni, G. (1993). Criteri di dimensionamento delle sovrastrutture di Catalogo.

European Central Bank. (2014). Retrieved January 28, 2014, from http://www.ecb.int/home/html/index.en.html

Faraggi, V., Jofré, C., \& Kraemer, C. (1987). Combined Effect of Traffic Loads and Thermal Gradients on Concrete Pavement Design. Transportation Research Record 1136 (pp. 108-118). Pavement Design.

Gulen, S., Zhu, K., Weaver, J., Shan, J., \& Flora, W. F. (2001). Development of Improved Pavement Performance Prediction Models for the Indiana Pavement Management System. Publication FHWA/IN/JTRP-2001/17. Joint Transportation Research Program, Indiana Department of Transportation 
and Purdue University, West Lafayette, Indiana, 2001. http://dx.doi.org/10.5703/1288284313192

Houben, L. J. M. (2009). The Dutch Structural design Method for Jointed Plain Concrete Pavements. Workshop Diverse uses of concrete IV, Nairobi, Kenya (pp. 1-16).

Loprencipe, G., \& Cantisani, G. (2013). Unified Analysis of Road Pavement Profiles for Evaluation of Surface Characteristics. Modern Applied Science, 7(8), 1-14. http://dx.doi.org/10.5539/mas.v7n8p1

Moretti, L. (2012). Modello di analisi strutturale, funzionale ed economica di pavimentazioni stradali in calcestruzzo. PhD Thesis, Sapienza University of Rome, Italy. Retrieved from http://padis.uniroma1.it/handle/10805/1657

Moretti, L., \& Di Mascio, P. (2013a). Model for estimating temperatures in concrete pavements. Model for estimating temperatures in concrete pavements. Proceedings of the first International Journal of Pavements Conference, São Paulo, Brazil.

Moretti, L., Di Mascio, P., \& D’Andrea, A. (2013b). Environmental Impact Assessment of Road Asphalt Pavements. Modern Applied Science, 7(11), 1-11. http://dx.doi.org/10.5539/mas.v7n11p1

Nishizawa, T., Ozeki, T., Katoh, K., \& Matsui, K. (2009). Finite Element Model Analysis of Thermal Stresses of Thick Airport Concrete Pavement Slabs. Transportation Research Record: Journal of the Transportation Research Board, 2095(1), 3-12.

Qin, Y., \& Hiller, J. E. (2011). Modeling the Temperature and Stress Distributions in Rigid Pavements: Impact of Solar Radiation Absorption and Heat History Development. KSCE Journal of Civil Engineering, 15(8), 1361-1371. http://dx.doi.org/10.1007/s12205-011-1322-6

Rao, C., Barenberg, E. J., Snyder, M. B., \& Schmidt, S. (2001). Effects of Temperature and Moisture on the response on the Jointed Concrete Pavements. 7th International Conference on Concrete Pavements Orlando, Florida, USA.

Shahin, M. Y. (2005). Pavement Management for Airports, Roads, and Parking Lots. Kluwer Academic Publishers.

Thomlinson, J. (1940). Temperature variations and consequent stresses produced by daily and seasonal temperature cycles in concrete slabs. Concrete Constructional Engineering, 36(6), 298-307.

\section{Copyrights}

Copyright for this article is retained by the author(s), with first publication rights granted to the journal.

This is an open-access article distributed under the terms and conditions of the Creative Commons Attribution license (http://creativecommons.org/licenses/by/3.0/). 